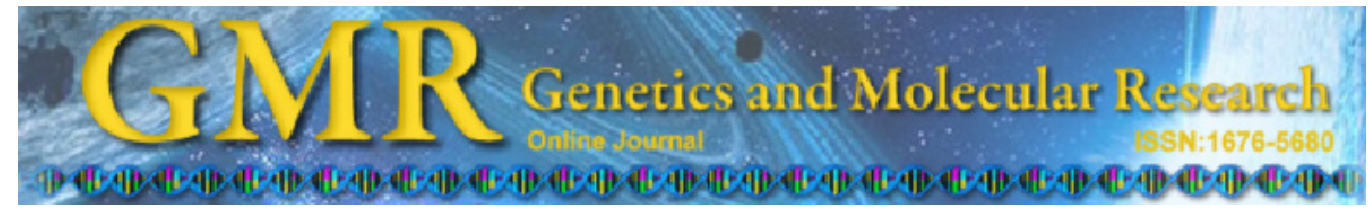

\title{
Identification of complex vertebral malformation carriers in Holstein cattle in south China
}

\author{
C. Wang, Q. Tong, X.Z. Hu, L.G. Yang, X.Q. Zhong, Y. Yu, J.J. Wu, \\ W.J. Liu, X. Li, G.H. Hua, H.Q. Zhao and S.J. Zhang \\ Key Laboratory of Agricultural Animal Genetics, \\ Breeding and Reproduction Ministry of Education, \\ Huazhong Agricultural University, Wuhan, China \\ Corresponding author: S.J. Zhang \\ E-mail: sjxiaozhang@mail.hzau.edu.cn
}

Genet. Mol. Res. 10 (4): 2443-2448 (2011)

Received October 25, 2010

Accepted March 20, 2011

Published October 13, 2011

DOI http://dx.doi.org/10.4238/2011.October.13.1

\begin{abstract}
Complex vertebral malformation (CVM) is a recently described monogenic autosomal recessive hereditary defect of Holstein dairy cattle that causes premature birth, aborted fetuses and stillborn calves. Guanine is substituted by thymine $(\mathrm{G}>\mathrm{T})$ in the solute carrier family 35 member A3 gene (SLC35A3). A valine is changed to a phenylalanine at position 180 of uridine 5'-diphosphate-N-acetylglucosamine transporter protein. CVM is expected to occur in many countries due to the widespread use of sire semen. We developed a created restriction site PCR (CRS-PCR) method to diagnose CVM in dairy cows. This was tested on 217 cows and 125 bulls selected randomly from a Holstein cattle population in south China. Five Holstein cows and five Holstein bulls were identified to be CVM carriers; the percentages of CVM carriers were estimated to be $2.3,4.0$ and $2.9 \%$ in the cows, bulls and entire Holstein cattle sample, respectively.
\end{abstract}

Key words: Complex vertebral malformation; CVM carriers; CRS-PCR; Holstein bulls; Holstein dairy cows 


\section{INTRODUCTION}

Complex vertebral malformation (CVM), first reported by Agerholm in 2001, is a lethal autosomal recessive hereditary defect in Holstein breed, which is caused by a point mutation from $\mathrm{G}$ to $\mathrm{T}$ at nucleotide position 559 in the bovine solute carrier family 35 member A3 gene (SLC35A3), which changes the amino acid sequence from a valine to a phenylalanine at position 180 of uridine 5'-diphosphate-N-acetyl-glucosamine transporter protein (Thomsen et al., 2006). The CVM gene exists in the Chinese Holstein population (Chu et al., 2008). If the proportion of CVM carriers in the nucleus breeding group of Holstein is high, it will cause a decrease in milk production and great economic losses in the dairy industry (Kearney et al., 2005). It is difficult to report the distribution status of CVM, because there is no detection technology with independent property rights in our country, so it is impossible to draw conclusions as to the route of transmission of CVM on the basis of parentage. The objectives of this study were to develop a technique for detection of CVM and to investigate the carrier frequency of CVM in a population randomly collected from Holstein cattle in south China.

\section{MATERIAL AND METHODS}

\section{Collection of samples}

A total of 217 blood samples from Holstein cows and 125 frozen Holstein semen samples were randomly collected in south China for DNA extraction using a standard procedure.

\section{Primer design and polymerase chain reaction (PCR)}

A pair of primers was designed to amplify 225 bp of the SLC35A3 gene, based on the genomic DNAsequence ofHolstein cattle(GenBank accession No. NC_007301.3) using the Primer3 software (http://frodo.wi.mit.edu/primer3) and dCAPS Finder 2.0 (available at http://helix.wustl. edu/dcaps/dcaps.html). The forward primer for PCR was 5'-GCTCTCCTCTGTAATCCCCA-3'. The reverse primer was 5'-CCACTGGAAAAACTAGCTGTGAGTA-3', which was engineered to introduce a point mutation at position 24 (italic) resulting in PCR products of CVM noncarriers containing an $R s a \mathrm{I}$ restriction site and products from carriers lacking this site. PCR was performed in a $20-\mu \mathrm{L}$ reaction mixture containing $1.5 \mathrm{mM} \mathrm{MgCl}_{2}, 200 \mu \mathrm{M}$ each of dATP, dGTP, dTTP, and dCTP, $0.2 \mu \mathrm{M}$ of each primer described above, $1 \mathrm{U}$ Taq DNA polymerase, $1 \mu \mathrm{L}$ genomic DNA and $1 \mathrm{X}$ PCR buffer was prepared according to the instruction manual for Taq DNA polymerase. Each reaction mixture in a $200-\mu \mathrm{L}$ Eppendorf tube was inserted into PCR apparatus at $94^{\circ} \mathrm{C}$, and held at $94^{\circ} \mathrm{C}$ for $10 \mathrm{~min}$ before the cycling reactions. Conditions of reactions were $30 \mathrm{~s}$ at $94^{\circ} \mathrm{C}, 30 \mathrm{~s}$ at $60^{\circ} \mathrm{C}$, and $30 \mathrm{~s}$ at $72^{\circ} \mathrm{C}$ per cycle, and 34 cycles were applied, followed by single reaction at $72^{\circ} \mathrm{C}$ for $10 \mathrm{~min}$ and cooling at $15^{\circ} \mathrm{C}$ for $10 \mathrm{~min}$. PCR products were analyzed on a $1.2 \%$ agarose gel with ethidium bromide.

\section{DNA sequencing}

The PCR products of cows and bulls were obtained from electrophoretic gels, and purified with the TIANgel Midi Purification kit (Tiangen Biotech, Beijing), and then sequenced 
bidirectionally using ABI PRISM 3730 to identify the accuracy of the products.

\section{Genotyping by created restriction site (CRS)-PCR}

In a $10-\mu \mathrm{L}$ reaction mixture, $4 \mu \mathrm{L}$ PCR products was digested with $4 \mathrm{U} R s a \mathrm{I}$ at $37^{\circ} \mathrm{C}$ overnight and genotyped by $8 \%$ acrylamide gel electrophoresis.

\section{RESULTS}

\section{CRS-PCR amplicon}

A 225-bp PCR product was obtained (Figure 1).

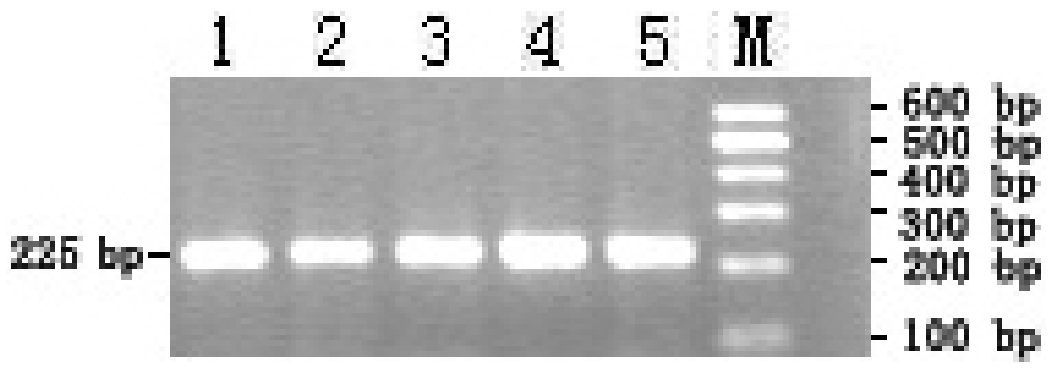

Figure 1. The 225-bp CRS-PCR amplicons of the SLC35A3 gene. Lane $M=100$-bp ladder marker. Lane 1 to $5=$ PCR product.

\section{The genotyping of CRS-PCR}

The 225-bp PCR products were digested with $R s a \mathrm{I}$ and discriminated by restriction fragment length polymorphism (RFLP). The PCR products obtained from CVM-carrier cattle DNA samples were digested into three fragments $(225,201$ and $24 \mathrm{bp})$, which was the heterozygote genotype GT; the CVM homozygote only had a 225-bp fragment with the TT genotype, and the healthy cattle showed two fragments (201 and $24 \mathrm{bp}$ ) with the GG genotype. The 24-bp DNA fragment was too small to be seen on the $8 \%$ polyacrylamide gel (Figure 2).

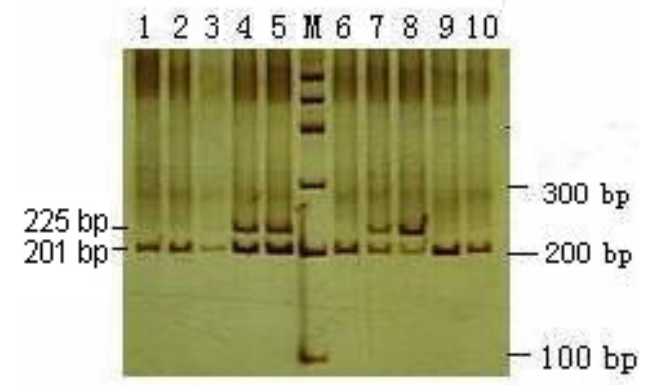

Figure 2. Genotyping by the CRS-PCR technique. Lanes 1, 2, 3, 6, 9, $10=\mathrm{GG}$; lanes 4, 5, 7, 8= GT; lane $M=$ 100-bp ladder marker. The 24-bp DNA fragment was too small to be seen on the gel. 


\section{Confirmation of the results of CRS-PCR by sequencing}

The PCR products from CVM carriers and healthy individuals identified by CRS-PCR method were sequenced by ABI PRISM 3730. There existed two alleles (G, T) in the nucleotide position 559 of SLC35A3 gene in CVM carrier cattle (Figure 3) and only allele G in healthy individuals (Figure 4). This indicated that this CRS-PCR technique was reliable and useful.

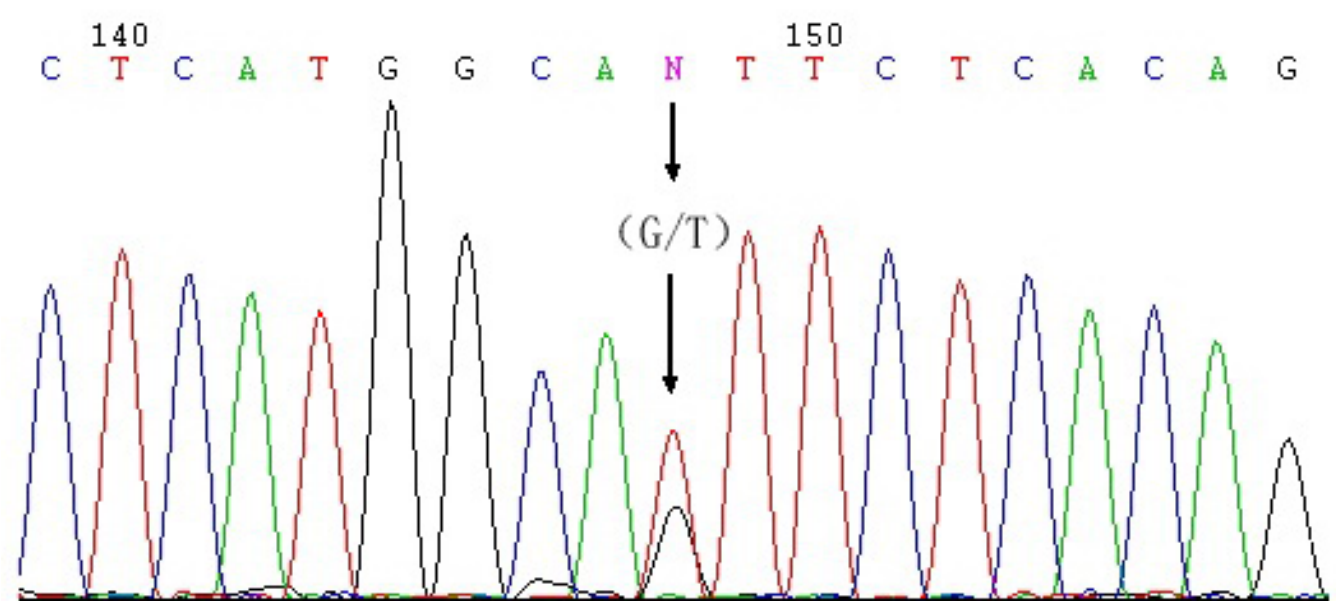

Figure 3. DNA sequencing of the SLC35A3 gene of CVM-carrier cattle.

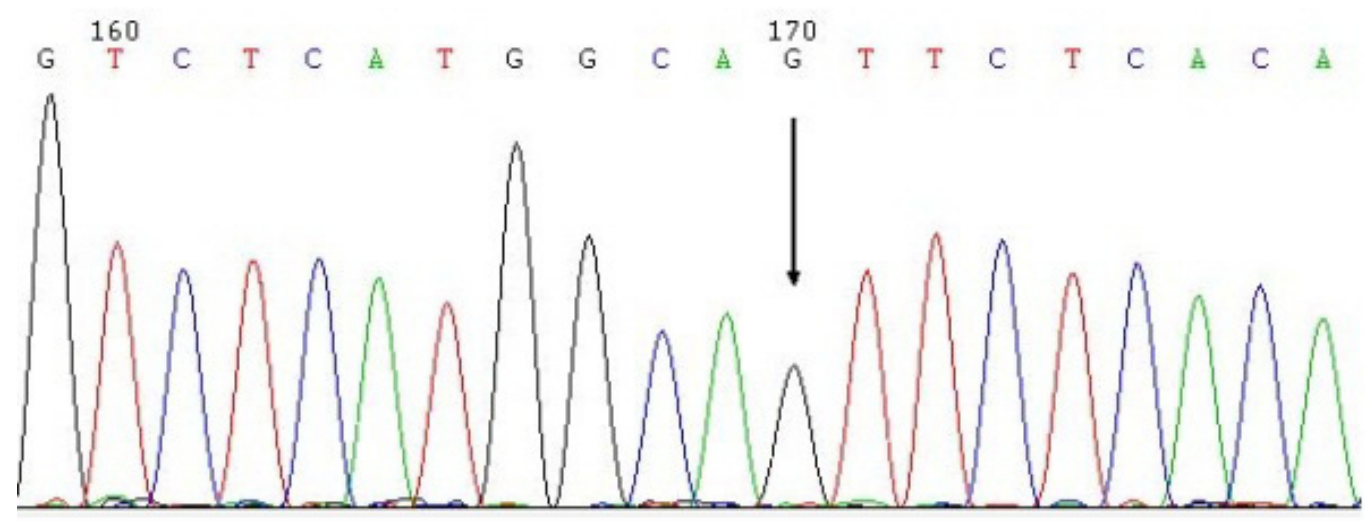

Figure 4. DNA sequencing of the SLC35A3 gene of healthy cattle.

\section{Genotypic frequencies}

A total of 342 Holstein cows were genotyped by CRS-PCR and sequencing; 10 heterozygous (GT) and 332 homozygous (GG) were discriminated, which 5 cow carriers were from 217 cows and 5 bull carriers from 125 bulls. The allelic frequency of the CVM mutation allele $\mathrm{T}$ in the population was $1.5 \%$, and the percentages of CVM carriers were estimated to 
be $2.3,4.0$ and $2.92 \%$ in the Holstein cows, Holstein bulls and whole Holstein cattle sample, respectively (Table 1).

Table 1. Allele and genotype frequencies of polymorphisms of the SLC35A3 gene.
\begin{tabular}{lccc}
\hline Genotype & Nenotype frequency & \multicolumn{2}{c}{ Allele frequency } \\
\cline { 3 - 4 } & & G & T \\
\hline GT & 10 & 0.0292 & $1.5 \%$ \\
GG & 332 & 0.9708 & \\
Total & 342 & 1.0 & \\
\hline
\end{tabular}

\section{DISCUSSION}

\section{Several methods used to detect CVM have been reported}

For instance, PCR-single-stranded conformational polymorphism (PCR-SSCP) (Rusc and Kaminski, 2007; Chu et al., 2008), allele-specific PCR (AS-PCR) (Bendixen et al., 2002; Ghanem et al., 2008), microsatellite symbol method (Berglund et al., 2004) and PCR primerintroduced restriction analysis (PCR-PIRA) (Kanae et al., 2005). However, CRS-PCR, applied in this study, is a simple and efficient technique to identify single nucleotide polymorphism (SNP) genotypes, in which one or more mismatch bases are introduced in a primer to create a restriction site by combining the SNP site after PCR. If there is no restriction site or the restriction enzyme is too expensive to use, CRS-PCR can be used to substitute PCR-RFLP, so CRS-PCR has been used extensively and effectively at present (Hosseini et al., 2006; Shayan et al., 2007; Batiz et al., 2009). In our study, RsaI restriction site was created to genotype healthy cattle (GG), CVM carriers (GT), and CVM homozygotes (TT), because there is no restriction site for G/T in the SLC35A3 gene. All CVM carriers and healthy individuals determined by CRS-PCR were confirmed by DNA sequencing (Figures 3 and 4). The results indicate that the CRS-PCR method developed in this study can be another potential technique for the reliable detection of CVM.

\section{The use of CVM carriers will inevitably result in economic losses in the management of dairy cattle herds}

Thus, many countries have carry out the detection of CVM and report the distribution of CVM carriers (Berglund et al., 2004; Thomsen et al., 2006; Rusc and Kaminski, 2007; Ghanem et al., 2008; Chu et al., 2008). The frozen semen and embryos of our country are imported from the United States and Denmark and other countries. Therefore, there may be some potential CVM carriers in China. The frequency of the CVM carriers was $2.92 \%$ in our study. Chu et al. (2008) reported that the percentage of CVM carriers in China was $43.6 \%$, much higher than our finding, because the Holstein cattle sample in their study comprised 68 frozen semen samples from at-risk Chinese Holstein bulls and 602 cows whose sires included 10 confirmed at-risk bulls; these bulls were selected according to the list of CVM carrier sires published by the United States and Canada, as well as the Chinese Holstein sire pedigrees, and probably were potential CVM carriers. In our study, 217 cows and 125 bulls were randomly collected from a Holstein cattle population in south China, whose pedigree and CVM carrier status were not clear, and this may be the reason that the percentage of CVM carriers in our 
study is different from that reported by Chu et al. (2008). Anyhow, the CVM gene exists in China, and it is essential to detect CVM and report the distribution of CVM carriers in the population of Holstein cattle in south China.

\section{ACKNOWLEDGMENTS}

Research supported by 863 High Technology and Development Project of China (\#2006AA10Z195 and\#2007AA10Z152), Ministry ofScience and Technology (\#S2010GR0947), Ministry of Agriculture in China (\#2010-Z16, \#2009ZX08009-142B and \#2008ZX08007003), Chinese Government (\#2009ZX08009-142B, \#2008ZX08007-003, \#S2010GR0947, and \#2010-Z16), Wuhan International Project (\#201070934339), and Grant of Innovation China UK Proof of Concept Project (\#ICUK PoC-RVC-003). We thank the farm staff who helped to collect all the relevant data.

\section{REFERENCE}

Agerholm JS, Bendixen C, Andersen O and Arnbjerg J (2001). Complex vertebral malformation in Holstein calves. J. Vet. Diagn. Invest. 13: 283-289.

Batiz LF, Roales-Bujan R, Rodriguez-Perez LM, Matas IM, et al. (2009). A simple PCR-based genotyping method for M105I mutation of alpha-SNAP enhances the study of early pathological changes in hyh phenotype. Mol. Cell. Probes 23: 281-290.

Bendixen CC, Svendsen S, Jensen H, Panitz F, et al. (2002). Genetic Test for the Identification of Carriers of Complex Vertebral Malformation in Cattle. World Intelectual Property Organization Publication No. PCT/WO 02/40709 A2 United States Patent: 7094544.

Berglund B, Persson A and Stalhammar H (2004). Effects of complex vertebral malformation on fertility in Swedish Holstein cattle. Acta Vet. Scand. 45: 161-165.

Chu Q, Sun D, Yu Y, Zhang Y, et al. (2008). Identification of complex vertebral malformation carriers in Chinese Holstein. J. Vet. Diagn. Invest. 20: 228-230.

Ghanem ME, Akita M, Suzuki T, Kasuga A, et al. (2008). Complex vertebral malformation in Holstein cows in Japan and its inheritance to crossbred F1 generation. Anim. Reprod. Sci. 103: 348-354.

Hosseini SY, Sabahi F, Amini-Bavil-Olyaee S, Alavian SM, et al. (2006). A novel accurate ACRS-PCR method with a digestion internal control for identification of wild type and YMDD mutants of hepatitis B virus strains. J. Virol. Methods 137: 298-303.

Kanae Y, Endoh D, Nagahata H and Hayashi M (2005). A method for detecting complex vertebral malformation in Holstein calves using polymerase chain reaction-primer introduced restriction analysis. J. Vet. Diagn. Invest. 17: 258-262.

Kearney JF, Amer PR and Villanueva B (2005). Cumulative discounted expressions of sire genotypes for the complex vertebral malformation and beta-casein loci in commercial dairy herds. J. Dairy Sci. 88: 4426-4433.

Rusc A and Kaminski S (2007). Prevalence of complex vertebral malformation carriers among Polish Holstein-Friesian bulls. J. Appl. Genet. 48: 247-252.

Shayan P, Eslami A and Borji H (2007). Innovative restriction site created PCR-RFLP for detection of benzimidazole resistance in Teladorsagia circumcincta. Parasitol. Res. 100: 1063-1068.

Thomsen B, Horn P, Panitz F, Bendixen E, et al. (2006). A missense mutation in the bovine SLC35A3 gene, encoding a UDP-N-acetylglucosamine transporter, causes complex vertebral malformation. Genome Res. 16: 97-105. 